\title{
Discussion on 4K Video Technology
}

\author{
Lehui Huang $^{1, \text { a }}$, Miaomiao $\mathrm{Li}^{2, \mathrm{~b}}$ \\ ${ }^{1}$ Education School, Jiangxi Science \&Technology Normal University, Nanchang, China \\ ${ }^{2}$ Education School, Jiangxi Science \&Technology Normal University, Nanchang, China

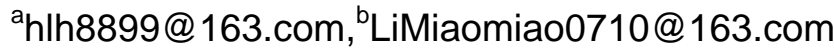

\section{Keywords: 4K, Imaging Technique; Video Products}

\begin{abstract}
When many people are still praising the amazing screen of new iPad, a kind of imaging technology with twice higher resolution ratio, 4k, enters into our sights. At present, SONY, Canon, Toshiba, sharp, JVC have released $4 \mathrm{k}$ video products, including flat-screen televisions, monitors, video camera, projector and other terminals. Although high prices and the lack of auxiliary products make it need more time to enter into the mainstream market, $4 \mathrm{k}$ video products, as the future development trend of the video display products, is the existence which can not be ignored.
\end{abstract}

\section{Introduction}

$4 \mathrm{k}$ images mainly refer to the image with $3840 \times 2160$ pixel resolution, expanded the full HD resolution twice in both horizontal and vertical direction. The UHD (ultra high definition, ultra-high resolution) has become the official name of the $4 \mathrm{k}$. In fact, there is another definition of $4 \mathrm{k}$ image, which is the image with higher horizontal resolution of $4096 \times 2160$ pixels. The resolution is defined for digital cinema by film industry groups.

If you'd like to know $4 \mathrm{k}$ product, you should start from of the relevant standards about $4 \mathrm{k}$ images first. The size of the image can be represented with pixel resolution, for example, the 1920 * 1080 resolution means that the image is 1920 pixels by the horizontal line and the vertical column is made up of 1080 pixels. For the reason of convenient communication, the industry often express the size of the image with the image pixel values on the horizontal direction, and in order to simplify the communication process, " $\mathrm{K}$ " is usually used to describe the pixel values, among them $1 \mathrm{~K}$ is equivalent to 1024 pixels, a few K refers to the image pixels on the horizontal line reach or is close to several times of 1024 .

\section{The dynamic development of $4 \mathrm{k}$ technology}

Nowadays, 4k resolution in the domestic technology engaged by TV, telecom operators and home appliance manufacturers refers to $3840 * 2160$ pixels. The pixel of $8 \mathrm{k}$ image developed by Japanese broadcasting association (NHK) with the name of SHV is four times of 4k images.

In addition to Japan, other countries also went into action. In January 2013, SONY announced that it would send services of $4 \mathrm{k}$ video in the USA in this summer. South Korean public radio and TV station KBS is preparing for carrying out the test broadcasting $4 \mathrm{k}$ video in microwave digital TV. Samsung electronics and large-scale VOD (video on demand) providers are also doing the test of sending $4 \mathrm{k}$ images. What's more, in addition to in television, $4 \mathrm{k}$ video playback function is also added in smart phones, tablet and other portable terminals.

Since the liquid crystal display technology era, the development of high-resolution screen has never stopped, even faster in recent years. Whether mobile phone, tablet PC, laptop or display, high resolution has been widely applied in the current mainstream products. The reporters get that, in the category of the monitor, the $2 \mathrm{k}$ (screen resolution reach $2560 \times 1440$ or 2560 x 1600) products are very rich, and the market is also very mature. However, as the high-end users pursue the display resolution endlessly, the consumer groups are growing, currently including SONY, Toshiba, Panasonic and other companies have introduced the display products supporting $4 \mathrm{k}$ resolution. Through showing you can see, $4 \mathrm{k}$ product has better performance, and the delicate degree of the 
picture is extremely increased. The personage inside course of study says, $2 \mathrm{k}$ market has been fully mature and reaches boiling point at present, and $4 \mathrm{k}$ will outbreak and make people's family entertainment experience to upgrade again.

So many facilities, such as content, storage, playback devices limit the rapid popularity of the 4 $\mathrm{k}$, but there is no doubt that $4 \mathrm{k}$ resolution still has a positive effect in the display area, whether in the domestic field, or in a smaller screen, $4 \mathrm{k}$ is needed. As technology advances, $4 \mathrm{k}$ will walk into homes one day.

\section{Difference between $4 \mathrm{~K}$ video technology and $2 \mathrm{~K}$ video technology}

The difference between $4 \mathrm{k}$ and $2 \mathrm{k}$ is not just the ascension of resolution. although the change of the resolution is the most intuitive feelings brought by $4 \mathrm{k}$ to people, at the same time, it also makes people ignore other important elements containing by $4 \mathrm{k}$ image, such as sampling method and frame frequency, color gamut and quantitative depth, high bit rate with the high storage requirements, and more abundant stereo effect matching with vision field. And these elements are crucial to enjoying the best telepresence and real sense according to human visual properties, visual angle and viewing distance. If closely look at existing $2 \mathrm{k}$ resolution pixels, the image "particles" is still serious. At the same time, HD resolution image can not meet the requirement of presence and reality after video compression, but compared with the $2 \mathrm{k}$, visual angle of $4 \mathrm{k}$ has been greatly enhanced.

Compare $4 \mathrm{k}$ with $2 \mathrm{k} \mathrm{TV}$, the difference is resolution. The resolution of $4 \mathrm{k}$ TV is $3840 * 2160$ while $2 \mathrm{k}$ TV is $1920 * 1080$.With pixel, $4 \mathrm{k}$ television is 8.2944 million pixels while $2 \mathrm{k}$ is 2 million pixels. The pixel of the former is four times than the latter, so $4 \mathrm{k}$ TV resolution is much higher than $2 \mathrm{k}$ television. Broadly speaking, in addition to the resolution, the color gamut of the $4 \mathrm{k}$ television coverage, contrast, brightness, interface, image display format, features and other performance indicators are superior to the $2 \mathrm{k}$ TV, especially the $4 \mathrm{k}$ TV is very strict in clarity and wide color gamut.

Specifically, the color of $4 \mathrm{k}$ television is richer and more nature than $2 \mathrm{k} \mathrm{TV}$, definition is more exquisite, you can even see clearly the fiber pores of the figures, which is not exaggerated. It is true that (the premise is 4k TV screen is large enough, at least 55 inches, otherwise the thrill of feeling will significantly reduce), and support more pictures, video, music files in different formats.

\section{4k video technology products}

Recently, many new home theater projectors have launched in the market, 4k VPL - VW1000ES projector, the world's first civilian level brought by Sony, is most prominent. In fact SONY developed SXRD chip with 1.55 inch and $4 \mathrm{k}$ level as early as the year of 2004, then applied at the projectors of business level. This year, through the design and transformation of the technical, SONY has developed a new SXRD chip with 0.74 inch and $4 \mathrm{k}$ level, precision of the pixels reaching $4 \mathrm{um}$, making the overall size of the projector reduce to the level of ordinary home theater projectors, thus promoting the VPL - VW1000ES projection to enter into ordinary families earlier .

Today, including SONY, Panasonic, Sharp, Samsung, LG, Hisense, Skyworth, Konka, Haier, TCL, Lenovo and other domestic and foreign manufacturers have introduced different sizes of $4 \mathrm{k}$ TV set. In the market, TV variety is rich, including 4k TV with 85 inch super size and those with 39 inch. The author required on Jingdong mall that the cheapest TV with 39 inches launched by konka only sell 2899 Yuan. Perhaps a few years ago we mentioned words about "full hd", "3 d" when talking about the TVs, but now $4 \mathrm{k}$ TV television industry has become a new swimmer. To buy a $4 \mathrm{k}$ $\mathrm{TV}$ at home does not need too much .

In recent one or two years, $4 \mathrm{k}$ TV sets of $50 \sim 60$ inches have been appeared on the market, but actually, more and more people have watched $4 \mathrm{k}$ images on $4 \mathrm{k} \mathrm{TV}$. Through ordinary image size put at home, we can also experience the third dimension based on high resolution and the real sense like looking at photographs. 


\section{The development bottleneck of $4 \mathbf{k}$ technology}

Some people think that, although $4 \mathrm{k}$ format is good, some films such as cartoon do not necessarily require $4 \mathrm{k}$ image quality due to the pattern problem of $4 \mathrm{k}$ and $2 \mathrm{k}$. Because animated film does not need so much information as $4 \mathrm{k}$, the $4 \mathrm{k}$ production cost is also too high, and projection equipment also needs to upgrade. In order to send $4 \mathrm{k}$ images to families, it not only needs to develop and manufacture receivers, but also needs to introduce commercial radio and television equipment supporting $4 \mathrm{k}$ video, which requires increasing the initial investment. Therefore, the threshold of the ultra fine imaging services service operators involving in is very high.

With the increasing of pixels, dynamic late film editors will fall into dilemma. Whether ordinary home computer can smoothly edit $4 \mathrm{k}$ images remains to be tested. The problem of storage capacity limit also needs a breakthrough. 4k is a double-edged sword, which can allow the users to obtain high resolution images, but also bring troubles to the ordinary consumers in the late edit and storage.How to solve these two problems, is also worth digital camera manufacturer considering. After all consumers having no digital single lens reflex are ordinary consumers, and home users are the main. Fool editing software is more enjoyed by this kind of people. To solve the troubles at present, the age of $4 \mathrm{k}$ video civil stage will come true. In addition, due to too high price and too little content and other bottlenecks, 4k high-definition TV still needs some time to truly realize population. If not reach the designated position, probably like OLED TV, early enter into the market, and do not appear in the color TV market until now .

\section{Conclusion}

Because of the development of science and technology, 4k video technology develops fast and becomes popular, and we can feel more clearly visual feast. As new home theater projectors release in the market, $4 \mathrm{k}$ video technology has gradually entered into the ordinary family, which will be a huge market development space. But there are many problems, like high cost of 4k image production, big previous input. How to improve the quality of infrastructure, reduce the cost of $4 \mathrm{k}$ video production, and make full use of the service brought by $4 \mathrm{k}$ image resolution, need video service providers and home appliance manufacturers to take the lead in development. From the point of the development trend of flat TV, 4k technology will become the focus of the development of color TV sets. After all, TV as the tools, the quality is the most concerned problem. And $4 \mathrm{k}$ picture resolution is very high and the screen size is also large. The author thinks that, only $4 \mathrm{k}$ high-definition TV is more and more rich in the film source, and the price is more civilianized, the comprehensive popularization is just around the corner.

\section{References}

[1] HanWei. Recent development of practical experiments of 4k high-definition video [J].Cable TV technology, 2006.07.20.

[2] Li Weisheng. The explore of the most popular video processing technology[J]. Home theater technology, 2011.11.01.

[3] Tian Lin, yujie Yang. Video content production under the age of $4 \mathrm{k}[\mathrm{J}]$. Film and television production, 2013.10.15.

[4] Zhuang Hongtao. Ultra fine image 4k technology development has emerged quietly[N]. Finance channel, 2013.04.18.

[5] Li Tao. Image’s revolution is happening[N]. Zhongguancun online, 2014.04.23. 